\title{
CRÔNICAS DE MALAZARTE
}

Barra do Pirai. O cetim negro da noite rasgavase, isso: rasgava-se, tombando aos pedaços pelos morros, além. A imagem não está má. Mina de Oiro Velho. Fazia frio, naturalmente. Quando não fará frio nas madrugadas de Barra do Piraí? Mas continuemos a imagem: Por detrás daqueles farrapos de cetim supra-citados, uns tons, róseos, isto é, esverdiróseos — os dedos da alva! - apareciam. Não; surgiam ou apareciam... Apareciam que é mais simples. Muito mais pobre, como convém à paisagem e mais... (Caixa d'água à beira da estrada). Parar num deserto como este, para a máquina beber água! Que diabo! máquina não é gente, podia-se-lhe regular a sede para sítios mais aprazíveis.

— "Cendrars!" É a voz de Oswaldo de Andrade, 
lá, de dentro do vagão, avisando que o chefe do trem almoça conosco em Nazaré. Mas vocês ainda não conhecem seu Sena! É chefe do trem. Que parte. Continuemos a crônica: Onde estava? Ah: o verbo aparecer é mais simples. E calha mais com o estado de alma presente. De quem senta sem cerimônia alguma numa escadinha de descida de vagão e... De descida ou de subida? As escadinhas são como a consciência: servem para descer os degraus do crime e subir ao pináculo da bem-aventurança. Reparem que eu não nego a consciência. Verifico apenas que as escadas tanto servem para descer como para subir. Paciência! Por isso resolvi ficar sentado simplesmente na escadinha e... Estou vestido de paragens simples. A simplicidade quase nativa $e$ ainda forte deste ainda e quase sertão. Como o adversário é necessário! Mas é verdade. Cada vez nos embrenhamos mais na tal simplicidade... quais são mesmo os qualificadores? "Quase nativa e ainda forte" do sertão. Creio que estou comovido. Ao menos: ninguém emprega a palavra nativo e a palavra forte então sem estar comovido. Exceto os oradores e os caixeirosviajantes. $\mathrm{E}$ os poetas parnasianos. $\mathrm{E}$ os modernistas também. $\mathrm{E}$ os penumbristas. $\mathrm{E}$ os namorados. E os. Qual, mundo!... todos vivemos a empregar adjetivos sem necessidade. Voltemos à simplicidade. Falo dos morros, das árvores $\mathrm{e}$ das águas. Rio das Mortes. Alguns panos de água estendidos na várzea a secar. Colinas mansas. Terra fraca de mau capim. Só zebu mesmo. Tudo tão simples! E imaginar que se um naturalista por aqui viajasse estragaria estes verdes naturais com os seus nomes gregos e latinos!... E os químicos e os... Ah! protóxidos de hidrogênio de dificilima digestầo! Mas a água de Minas é tão água! Que pureza! coada na barreira lustral dos granitos. Mas não há sábios em nossa roda. Tarsila do Amaral é n'alma a simplicidade nativa, preciso repetir o adjetivo, nativa e encantadora do Brasil. Principalmente agora, abandonado o cubismo. Não sei, mas tudo o que faz quadros como esboços é a própria simplicidade azul destes céus tupinaquis. Este azul que tanto influiu na fantasia decorativa dos pintores minei- ros. Falo dos pintores bem mineiros, legítimos primitivos, criadores de algumas obras primas que se estragam lentamente. Na matriz de São José d'el-Rei, por exemplo, há uma tela corrediça no altar-mor que é maravilha. Inifinitamente superior, como comoção e como pintura, aos dois quadros laterais, italianizinantes sábios e sem valor. Há em Minas toda uma série de primitivos admiráveis. Escola que morreu inúbil, porque os ouros se escoaram no lamento dos ribeirões e o esplendor morreu prematuro. Naquele tempo os paulistas não pensavam no dia seguinte. Amostra: aquele coronel Antônio de Oliveira Leitão, truculento e inativo, orgulhoso e emperrado. Enquanto isso os emboadas (vide metecas) se desenvolviam nos pequenos comércios. Ainda hoje é a mesma coisa!... Agora que estou reparando: não há poeira no Oeste de Minas. É sempre assim: a gente só repara nos bemestares que goza quando sente a falta deles. Não há poeira, garanto. Se isto continua até Divinópolis, que delícia ${ }^{1}$ Mas, voltando ao assunto, que maravilha caída do céu a nossa Tarsila! Tomou-a agora um fogo sagrado... Os olhos brilham. A voz firmou-se enérgica, verdadeira. Que é de Paris ${ }^{2}$ ? Que é do cubismo?

- Não, Malazarte. Volto a Paris, mas para me aperfeiçoar ainda mais nos processos de restauração de pinturas. Depois venho para Minas. É preciso conservar tantos tesouros. Eu estou pronta. E sem nenhuma paga. Que remuneração melhor para mim que restituir à pequena e maravilhosa Rosário de S. José d'el-Rei o esplendor passado do seu teto? Toda a minha vida que se resumisse nisso... eu seria feliz! Gosto das grandes empresas.

Como! pois aquela casa é um colégio! "Sim senhor... Colégio Padre Nicolau!! Mas que Nicolau mais extraordinariamente padre, este! Em pleno deserto! Lembra-se do Caraça?... Naturalmente ensina-se a retórica e o... Partimos. Cendrars vem ter comigo espantado. - "Imagine, Mário! paramos só para entregar uma

1. Correção M. A.: no texto do jornal: "dilícia".

2. Idem: "Que é Paris?" 
carta! "Quelle merveille!"

Este "quelle merveille" do Cendrars já caceteia. Parece até o refrão da Petite Jeane de France... "Diz, Blaise. Sommes-nous loin de Montmartre?" Mas vocês não imaginam, quanta maravilha! Nós só dizemos isso. Menos o Godofredo da Silva Teles, que não tem a admiração expansiva. Fica mudo, como distraído, perplexo. Que é do Godofredo? - Não vi; que é do Godofredo! De certo já subiu a ladeira. - Mas ele não sabe quem tem a chave da igreja! Fui-lhe atrás. passou por aqui um moço de São Paulo?

- Um moço bem vestido, olhando muito sério? - É. - Passou, sim senhor. Subiu. Também: em São José ${ }^{3}$ d'el Rei, moços bem vestidos só quase que nôs. Miséria. Mornidão. Alguns cinzeladores. E uma olaria, ajunta o José Ferreira Gomes, escultor, sacristão e pirotécnico. Foi ele que fez o Judas queimado, ontem em São João. Um Judas admirável, palavra! Mas fora tijolos, correntinhas de prata e foguetes: nada. Cada um vive pra si. Que acontece? A população (excetuados uns poucos, é evidente) anda de pé-nochão. A calça rasgada na perna direita, acima do joelho. Que se vê? Sempre a mesma pele cor de areia das margens do Paraopeba. Cansaço. Mornidão. Que é da grandeza antiga? Essa dorme sono de cobra, enorme, tombando aos pedaços, apodrecida pelas goteiras, na Trindade, no Rosário, na casa de Tiradentes. É pena. Quanta obra de arte a se estragar!

Existe o esplendor nascente das novas Minas Gerais. Gente ardida, que já não crê mais no oiro fácil, e paciente à frutifícação anual das lavouras. Mas isso está longe. Nós andamos em busca de arte e de passado. Chegamos a exasperar a ambição cansada daquela gente. Tomaramnos até por negociantes de quinquilharias antigas. Só o Osório, com seus doze anos curtos, caçoou. Teve uma boa. Tarsila adquirira uma Santa Ana. Eu, o quadro. Osório pediu-me que fosse com ele até lá. Atingimos o meio da praça. Queria saber o que estava escrito na pedra. De-

3. Ibidem: "São João". pois que lhe operei a cegueira daquele latim, repetiu as palavras e a tradução. Quando voltávamos o fu... (JOÃO PINHEIRO). Ué! Música na estação... Que será? Vai embarcar. Embarcou. Estas maçãs serão daqui? O Godofredo, fazendeiríssimo, se irrita: "Isto não é Juiz de Fora ou Belo Horizonte. Então a gente deste lado é capaz de plantar mais do que come?" Modorra. Pasmaceira. Que pobreza! O trem engasga. Dá um arranco. Todos sobem. Vai. Que negros mais diversos! Cabindas, monjolos, minas... Da Beleza à hediondez. Espero o "Quelle merveille!" Onde estará Cendrars? Mas, voltando ao assunto, quando vínhamos do monumento, Osório, vendo a sofreguidão com que comprávamos coisas velhas, largou o risinho: "Essa pedra também é muito antiga. Quem sabe se vocês não querem levar ela para São Paulo...

- Mário, metez dans votre chronique: "Je vois une fazenda tres sale. Le chef du train dit qu'elle a des vieilles peintures magnifiques".

Ah! se pudesse mandar parar o trem, como fizemos com o especial de ontem no Capão da Traição... Godofredo dizia-me duvidar um pouco do caso, como está contado. Belazarte protestou, comovido. Olhava o chão. Que é Belazarte?

- Se eu encontrasse ao menos um maxilar de paulista por aqui!...

- Nazaré! Nazaré! Levanta! o almoço!

$\mathrm{O}$ trem andava ainda. $\mathrm{O}$ bando de abutres-viajantes cai sobre a mesa. Mas o Osvardo (depois do manifesto pau-brasil assim chamado) e eu operamos o prodígio...

- Esse lugar está ocupado! — Não senhor, faz favor! Já virei essa cadeira!... o prodígio de tomar sete lugares. Se o René Thiollier ainda estivesse conosco, - que pena! - seríamos oito. Sentamo-nos. E vemos este espetáculo admirável: Muito digna, intrépida paulistana da boa têmpera, sorridente sempre, grande dama mesmo entre aqueles caixeiros-de-rapina esfaimados, Dona Olivia Guedes Penteado, à espera 
que eles se fartem, para se reconfortar. Tarsila com um papel encardido, comovente na mão:

- O chefe do trem está me mostrando uma charada em verso escrita por uma mocinha que já morreu e que foi namorada dele em 1889.

Osvaldo jura que mais tivera a intenção de abandonar Paris para vir encontrar o Senna em S. João d'el Rei. E o Senna corre sempre, ao lado da pintora, murmurando a história triste da proclamação de República.

- Sua mulher sabe disso?

- Não. E a outra já morreu. Era muito bonita. Cantava na igreja tão bem! E por causa dela estou viajando até hoje. A gente vai pra cá, pra lá. Vê tantas coisas!... Disfarça (IBITURUNA). $\mathrm{O}$ trem pára. Isso disfarça as lembranças de seu Senna, que vai mostrar o antigo arraial. -- Mas diga, seu Senna: Sua mulher não sabe que o senhor guarda essa charada?

- Não sabe, não. Ela é ciumenta, meu Deus! Mas tenho uma mala que nunca vai em casa. Está cheinha de cousas! Eh! se eu morresse de repente, ficava comprometido.

$\mathrm{O}$ arraial antigo aparece, que lindo! a igreja sempre no alto... O casario branco, de teto levemente chinês, desvia as lágrimas de Senna. A paisagem começa a interessar outra vez. Olhe que ponte! como na Índia. Viaja-se pela Ásia inteira. Já tivemos no Tibé, junto à vila das Águas-Santas. Mais do que o Tibé, tivéramos a surpresa de encontrar lá uma velha senhora paulista de familia conhecida. Ficou chorando a pobre! a mostrar meio rosto de lágrimas pelo portal. Talvez pela primeira vez na vida por nossa causa, horrorizada com o próprio desterro... É sempre assim. Fazer um bem, fazer um mal. Ninguém sabe os gestos onde vão parar. Tudo é escada neste mundo! (AURELIANO MOU$\mathrm{RÃO}$ ); aqui seu Senna se separa de nós. Posso escrever-lhe o nome com um ene só. Seu Sena. Que maravilha! Tem só três dentes espaçados na frente. Que nem são dele. São de oiro. Um grande no meio. Dous menores dos lados.
Quando seu Senna ri fica mineiro 4 . Parece nave escura de qualquer igreja colonial com o altarmor e dous altares laterais em talha doirada. Seu Senna tem um riso que é a matriz de S. João d'el-Rei. Adeus! Até outra vista!

Mas, como nos discursos fúnebres, seu Senna não partiu, ficou. Nas nossas recordações quase tanto como o interior de Sto. Antônio. "Quelle merveille"! Na cidade morta, o deserto, modorra, a grande igreja eleva as torres curtas. Nada que ver por fora. Não tem a originalidade do Rosário de Ouro Preto, nem a graça amaneirada de S. Francisco de S. João d'el Rei. Mas nenhuma outra igreja destas Minas guarda melhor o exemplo do faustoso sec. 18 mineiro. Sua capela-mor é a única obra de talha no Brasil que se possa comparar, como perfeição de acabamento a S. Francisco da Penitência do Rio. Obra de reinois, não há dúvida. Destaca-se completamente como técnica e mesmo como estilo dos outros altares da igreja. Igualmente ricos. Mas o entalhe é mais tosco, a invenção mais pobre, ou por outra, menos sabida. E o esplendor do coro, o luxo pictural das sacristias! Oh!...

Diante disso que papel fazem as nossas igrejas modernas de S. Paulo! Não se poderia então aproveitar dessa abundância, que é já nossa também, elementos que não fossem góticos! Mas só o gótico é místico, não é? E esse aleijão da nossa catedral se construiu. Aleijão antes de nascer. $E$ a cúpula, que é também a seu modo "une merveille"! Que há também as maravilhas da estupidez. (OLIVEIRA). Esta máquina faz tal barulho aos meus ouvidos... Irra! máquina dos quintos! Vai pro inferno com todas as Goticidades Arquitetônicas que não enumerei na minha "Paulicéa"!

Estou irritado. Verifico esta raiva e paro. E paro... Crônica difícil esta... começo os assuntos: não os continuo... Mas para que continuar? Tudo está na ventura do começo. Já me caceteia esta viagem. No entanto ao partir, Cendrars, Noné e eu cantávamos. É isso. Ardências do

4. Correção M. A.: no texto do jornal: "maneiro". 
100 ANOS DE MÁRIO

principiar!... Depois vem o cansaço. Eu, queria ainda dizer que os arquitetos neo-coloniais são quase tão idiotas como as Goticidades Arquitetônicas... Pois é: não vê que estão a encher as avenidas de São Paulo de casinholas complicadas, verdadeiros monstros de estações balneárias, de exposições internacionais. Porque não aproveitam as velhas mansões setecentistas, tão pobres! tão harmoniosas! E sobretudo tão modernas pela simplicidade do traço? Em vez, não; sujam a Avenida Paulista com leicenços mais parecidos com pombais feitos por celibatário que gosa aposentadoria. Estou irritado. Pombais? Nunca pombais para essa nobre sociedade paulistana, e velha (além dos ítalos recém-nascidos, já se vê) que em vez de partir de Taubaté em novas bandeiras prolíferas, anda a misturar os leitos estéreis. Isto em português da gema se chama: "Escândalos sociais". Mas eu não vou começar um novo assunto agora que a crônica está no fim! Seria demais, não, passadistas? Olhe a paisagem, Tarsila! Que é do Osvaldo? Godofredo raciocina. Cendrars está no 1.364.8330 "Quelle merveille!" Dona Olivia Guedes Penteado sorri deslumbrada, sempre ativa, incansável. Há também as de lamê que se tiranizam em eternos saraus, sem forças para um quilômetro a pé... Mas nós rodeamos aquela que com a mesma graça e imperturbável perfeição sabe pisar salões nobres e sentar-se ao lado dos dançadores do Bloco "Aguenta, mas vai!" Que outra dama de Higienópolis se arriscaria a esperar trens mineiros na Barra de Piraí? Isso eu ia perguntar no começo desta crônica quando me distrai, fui caminhando e que engraçado! Cheguei ao ponto de partida. Eu sabia bem disso. Há uma ordem misteriosa que dirige pensamentos e mundos! Tanto faz descer como subir ${ }^{5}$ Deixar-se levar assim... É bom! O trem para em Gonçalves Ferreira. Que gentileza excepcional a destes mineiros! Espantoso! Demorarão um pouco mais a partida para que jantemos sossegados. Desço do vagão e...
Este texto foi extraido de BATISTA, Marta Rossetti, LOPEZ, Telê Porto Alcina, LIMA, Yone Soares de (Pesquisa, seleção, planejamento). BRASIL: $1^{o}$ tempo modernista - 1917/ 1929. Documentação. São Paulo: Instituto de Estudos Brasileiros, 1972. p. 109-115.

Nota da redação: Agradecemos ao Sr. Carlos Augusto Andrade que, gentilmente, nos cedeu os direitos de publicação do artigo de Mário de Andrade.

5. Nota M. A. de.: frase à margem. 